Brit. J. vener. Dis. (1960), 36, 106.

\title{
GROUP DISCUSSION WITH MALE V.D. PATIENTS*
}

\author{
BY \\ A. J. DALZELL-WARD \\ Central Council for Health Education
}

AND

C. S. NICOL AND M. C. HAWORTH

British Federation against the Venereal Diseases

Health education has always been a prominent feature of activities aimed at the prevention and control of venereal diseases. It is notable that educational efforts are redoubled during wars, which are notorious as episodes during which there is a heightened risk of the spread of venereal infection. So far, however, these efforts have remained at the level of propaganda-that is, the issue of warnings of the dangers of venereal infection, with or without some information as to the nature of the venereal diseases, but always urging people to obtain medical advice. The methods adopted have included the use of mass media of communication by poster and the written word, and by talks or lectures to selected groups, such as service men or youth club members. In some cases the subject has been included in a syllabus of "sex education".

Such a policy has been based on the oversimplified premise that if people possess the knowledge they will order their behaviour accordingly. Professional health educators were amongst the first to recognize that this was a general fallacy, and that behaviour related to health practice was determined by motivation which in turn was governed by attitudes, beliefs, group loyalties, and degree of emotional maturity. It is remarkable that this has not been more generally recognized in the field of venereal infection, for we find that Wittkower and Cowan (1944), when working with Army patients, showed that personality traits were responsible for the promiscuous behaviour which had led to venereal infection.

These authors specifically state that promiscuity of the types which lead to venereal infection is seldom the result of positive mature sexual interest, but is mainly the result of attempts to relieve acute

* Paper read to General Assembly of the I.U.V.D.T. in London on October 14, 1959. psychological stress. Therefore neither punishment nor "evil counsel" is likely to affect the issue to any marked degree.

A sub-committee of the British Federation against the Venereal Diseases (1958) decided to examine the effectiveness of existing mass media on a sample of patients attending special treatment centres for the first time. Of 292 patients ( $231 \mathrm{men})$ in London and Newcastle, only 85 said that they had read books or articles on sex and/or venereal diseases, but 200 men had seen posters on the subject. These had not prevented the behaviour which led to their attending the clinic and the only poster which had produced any effect was the one advertising the address of the clinic to which they had reported. It was concluded that all the patients were aware of the way in which venereal disease is contracted.

This was a preliminary investigation which supported the contention that a new approach to health education in this field is required. It is an axiom of health education practice that a preliminary study of attitudes and motives is necessary before planning a campaign. The problem, therefore, was to find some method of studying the attitudes of a sample of patients. The task was started with the assumption that promiscuous sexual behaviour is the soil in which venereal infection mainly flourishes. From the purely epidemiological point of view it is obvious that the greater the number of contacts the higher the risk, and indeed Wittkower and Cowan (1944) found that venereal infection was predominantly the result of true promiscuity-here implying transient contact-and not of other forms of extra-marital intercourse.

Studies of the personality of male venereal patients have been carried out by Wittkower and Cowan (1944), Wittkower (1949), and Watts and Wilson (1945). Such studies have been psychiatric in character and have produced a personality assessment obtained at individual interview. 
Wittkower and Cowan studied a random sample of $\mathbf{2 0 0}$ male patients in the Army and compared them with a control group of 86 male patients with impetigo. They found that 38.5 per cent. of the sample were habitually promiscuous, but by applying the test of "transient" sexual intercourse as opposed to intercourse with a regular contact, promiscuous behaviour could be ascribed to the majority of the group. There was no evidence of glandular effects producing an exceptional sex urge and no evidence which could support a contention that sexual activity represents a simple need which has to be satisfied. This is an important finding in view of the beliefs revealed by the male patients in this present study.

Wittkower and Cowan go so far as to say that the wide range of human erotic and sexual interests cannot be explained in terms of single and specific psychological needs. Their conclusion was that habitual promiscuity is related to an incapacity for deep attachment to any one woman or to a deficient amalgamation of feelings of affection and sexuality, originating in a disorder of emotional development. They found also that promiscuity was a matter of "morale rather than morals" and described cases in which maladjustment to Army life had been the initiating factor.

A similar view was put forward by Watts and Wilson (1945) in their studies on Canadian Army personnel with venereal disease. In this study 292 consecutive cases of venereal disease were examined and the main personality traits of the patients identified in four categories:

(1) Unstable men who do not control themselves in any aspects of their lives;

(2) Heavy drinkers;

(3) Promiscuous men who are immature in attitude and behaviour;

(4) Men who are too dull to be good soldiers.

Watts and Wilson also emphasized the importance of emotional factors in venereal infection and pointed out that the curing of a urethral discharge or penile sore does not influence the established habits of behaviour which contribute to the acquisition of venereal disease. Such a view is supported by Wittkower (1949) in a later paper. He found that there was a history of a broken home in 60 per cent. of a sample of venereal patients and that 80 per cent. of his female patients had unresolved conflicts regarding their families. Other characteristics were an irregular work record, delinquency in some cases, heavy drinking in 30 per cent. of males, and general neurotic trends in 43 per cent. compared with 5 per cent. of a control group.

\section{Plan of Present Study}

This, then, is the background of knowledge against which the present study was carried out. The work referred to was psychiatric in technique and aimed at identifying psychodynamic factors. It was therefore diagnostic in character, but it could not be applied directly to health education techniques. For this purpose a survey of attitudes and beliefs and even a study of the language used by patients was required.

It has been recognized for some time that group discussion is the best technique both for attitude identification and for attitude change, and several controlled experiments have been carried out in recent years which support this contention. It was therefore decided to conduct experimental sessions with small groups of male patients who had attended special treatment centres in London. The three objectives were to promote free discussion on personal attitudes to venereal disease and to sexual promiscuity; to identify personality traits which might be operative; to obtain ideas for a more effective educational approach, as distinct from propaganda.

One of the main points of technique in group discussion is for the leader to prepare stimulating questions to initiate the discussion, which is then allowed to proceed until such time as the leader decides to intervene or to turn the discussion in another direction. For this purpose a series of questions was drawn up as follows:

\section{Stimulating Question}

Recently there was a scene near Charing Cross when a woman gave a man a black eye. The onlookers could tell from shouts that she was a prostitute and that the man had not paid her. Two policemen arrived and arrested them both. The spectators thought that it was a bit tough to arrest the man as well. I wonder if that is a general opinion?

\section{Specific Questions}

(1) Are there two kinds of women ?

(2) Is sexual activity any concern of the community?

(3) Is continence (leader will define) harmful?

(4) Some people say that sexual intercourse is like inflicting punishment on women. Do you agree?

(5) With a "pick-up" there is no need to bother about getting her to agree. Is this an advantage ?

(6) I wonder how we feel when we first realize that our parents have a sex life.

In practice the opening statement was sufficient to initiate the discussion and it was found that answers 
to the remaining questions emerged spontaneously. After some experience had been gained with this type of group, alternative openings were used, for example: "Let us look around this group and decide what we all have in common". None of the men had seen the questions beforehand and the paper on which they were typed was kept out of sight, as the intention was to produce a relaxed and informal situation.

The men volunteered to attend the discussions and the approach was made to them by the almoner at a large London Special Treatment Centre. To those who expressed interest in the idea the following statement and form of consent was issued. It should be noted that an effort was made to create confidence and to explain the purpose of what was, for them, an unorthodox proceeding. As the discussions were tape-recorded it was important to stress that anonymity would be preserved.

\section{Statement to Volunteers}

Although the modern treatment of V.D. is efficient, prevention still remains better than cure. Prevention is concerned with individual behaviour as well as with the treatment of all infected people in the community.

What led men and women to the events which resulted in their contracting V.D. ? If we can get the answer to this question then our educational efforts can be more effective. The whole community will be grateful to the anonymous helpers of whom you are one, for the aid they have given doctors in seeking a clue to this problem. You will not be asked to do anything difficult, but simply to talk. You will be asked to meet a small group of other men who are under treatment for V.D. and to talk freely with them. The doctor in charge of the investigations will put certain questions to you all and you can say anything you like and express any ideas which occur to you. The conversation will be recorded but you can be assured that all that you say will be treated in the strictest confidence and that your name or any other mark of identification will be strictly excluded from the recording.

\section{FORM OF CONSENT}

I, ................, hereby give my consent to take part in group discussions organized by the British Federation against the Venereal Diseases.

I understand that the object of these discussions is to further research into behaviour which may be the cause of V.D. I understand that the discussions will be recorded and $I$ accept the guarantee given by the British Federation against the Venereal Diseases that strict anonymity will be preserved, and that the recording will be used for study only by professional people officially engaged in the campaign against V.D.

I understand that extracts from the recordings may be published in scientific journals for the purpose of serious research.

Signed................

\section{Procedure}

Patients. - In all seventeen men volunteered to take part in the discussions. Their ages ranged from 19 to 48 years but with two exceptions were all under 30. Their background was varied and as the rules of anonymity precluded any knowledge of their occupation or residence only a superficial impression could be gathered as to their social status. Two only had had higher education, judging by speech and their use of words, but it was remarkable that all the men could express themselves eloquently and clearly and showed some insight into the behaviour problems under study. They entered into the discussion with enthusiasm and they were by far the easiest group that the writer has handled. Although they were strangers when they assembled they freely exchanged views and experiences and there was an absence of tension or inhibition.

Discussions.-Five sessions were held. The first batch of seven patients attended for a second session, and the remaining ten attended three sessions of four, two, and four members respectively. The leader initiated the discussions with a brief introduction, put the statement referred to, and then remained unobtrusive. From time to time it was useful to halt the discussion to produce a critical analysis, such as:

"I am interested to hear you all declare that a sexual outlet is a social necessity, and yet you use expressions of disgust when referring to prostitutes-now why is that?"

If a member made a vague statement, then the leader pressed him to amplify it. For example, when one member said: "The way society is at present", he was asked to explain exactly what he meant.

Sessions lasted about 2 hours each and the entire discussion was recorded on tape. A social character was imparted to the occasion by the provision of coffee and biscuits.

\section{Results}

It must be emphasized that this work was entirely experimental and in the absence of control groups it is not justifiable to claim that the attitudes revealed in the discussions are specific for patients with venereal disease.

A selection of extracts from the tape-recordings is given below. They reveal that it was generally assumed that sexual continence was, if not impossible, harmful; that prostitution is necessary to provide the outlet for the "natural" sex urge; that 
organized brothels are the necessary corollary to this; that there are two scales of values applicable to women as a class-there was a consistent use of the term "a decent girl" or "a nice girl" to mean one who would not accept a promiscuous relationship.

\section{EXTRACTS FROM TAPE-RECORDINGS}

\section{EXTRACT 1}

Leader. You say that sex-meaning sexual intercourse -is necessary for men. You say that what is called technically continence, that is, not having any sexual activity either outside marriage or, if unmarried, not at all, you would say that was harmful?

Speakers. Depends on the individual . . average healthy men. ...

Leader. You say what you think-I am not indicating approval or disapproval of anything you say.

Speaker 1. I think that it is necessary.

Speaker 2. I agree that it is necessary.

Speaker 3. I think it is desirable, but not necessary.

Speaker 4. I think it is necessary, mentally speaking.

Leader. In what way?

Speaker 4. In my own personal view, I think that when I say it is necessary from an emotional point of viewmental point of view-it brings you to a safe (?climax) ... that you can't get under any other form, in any other way. There's no other way to get that emotional atmosphere, bar that. And I think that, even more so, if you are a with a prostitute because, as I said earlier, I firmly believe that it does to a certain degree attract some people-I know it does me.

Leader. Do you distinguish two kinds of women, then?

Speaker 4. Yes, definitely. With a prostitute I would have no respect whatever for her, I think that's about as far as it goes, it's just clean-cut with me. Whereas a woman who wouldn't let you go with her just like that-a piece of cake-that woman I would have respect for; on the other hand, if she was easy-easy meat for you-I would think of her just as I would a prostitute-no respect!

\section{Extract 2}

Speaker 1. But what I mean is that it is convenient if you are feeling that way one night, we'll say. It might often be that you are in a situation whereby you could probably get intercourse if you went the right way about it, but you're not really all that interested that night. But another night, when you're really interested, there's no chance in that direction, and so the only and most convenient way is to go to a prostitute.

Speaker 2. I can't understand you being more interested in a prostitute than, say, a love affair with a nice girl, because to my mind a prostitute is just dead mutton-it's just any port in a storm that will do because there is nothing else better. Now that's how I view a prostitute.

Speaker 1. Oh, I don't have any special liking for them. I just say that they are a convenience for which there is no replacement.

Speaker 2. All right. You just said-the first thingthat you thought sex was a necessary thing.

Speaker 1. Yes, emotional.
Speaker 2. An emotional thing. It was not just the fact that you had slept with a woman and that was that. Now you are saying just the opposite thing: because she's the easy way out. It may be that she is an empty-whatever one can call it-a body on which you can satisfy yourself. This is not an emotional thing; this is just lust.

Speaker 1. Well, yes, let's call it lust. But still, to my mind, that is what I mean when I say it is mental, not just physical, you see. I firmly believe that when one is satisfied for another length of time, mentally speaking.

Speaker 2 . I personally get no satisfaction from sleeping with a prostitute whatsoever, mentally-just the opposite, just physically.

Speaker 3. Well, I definitely think that prostitution is a convenience for lots of people. It depends on the circumstances. In a lot of cases - a man can be unmarried, be unhappy-a prostitute can be his answer. Then, again, you get a single bloke who doesn't want to be bothered about going steady with anybody. A drawback in his mind if he has intercourse with a girl is the risk of having a child, and he's got to get married. There's all those points to be considered. I think prostitutes definitely do play a part, and you can't deny it.

Leader. But you don't get any emotional satisfaction from going with a prostitute yourself?

Speaker 3. No emotion, no.

\section{Extract 3}

Speaker 1. While I sometimes would not think twice about going with some loose woman, I would certainly think twice about having intercourse with a girl who I firmly believed had never had intercourse. In fact, I can firmly say that I would not be the first, I would not do that.

Leader. Why would you not do that?

Speaker 1. Well, because with a prostitute I am not doing any harm. The harm has already been done, and in fact she is inviting you to do it, she wants you to do it. But with a girl who has not had it before you can very easily provoke her to do it-it's the natural thing-and therefore she's pretty well defenceless, if she thinks quite a bit of you, that is.

Speaker 2. May I ask a question of my friend who just spoke: would you marry a prostitute?

Speaker 1. Certainly not, no.

Speaker 2. What happens if you met a woman, a girl, you fell in love with her, you did not know anything about her, and just before you got married she said: "Look, I must confess to you, I can't keep it a secret any more, I have been a prostitute", and you are really in love with her-what would you do then?

Speaker 1. I do not honestly think that I could marry that girl, I don't really think I could. Of course, I would have to be faced with the situation, but I don't, speaking now, think that I could bring myself to marry her.

Speaker 2. Are you in love-have you been in love? Speaker 1. No.

Speaker 2. So you don't know really what would happen.

Speaker 1. No. But I say now, I don't think I would be able to bring myself to it. If I did, I would be overcoming quite a part of my mental make-up.

Speaker 2. And another question I thought of when you said that is this: you said that it is easier to go with a 
prostitute-would that be because ... with an ordinary girl you have to do partly what she wants, and you have to think of her some of the time. With a prostitute, you know that she does not count, you've paid your money, you take the choice. She's just there-it's a question of doing what you like. If you decide to go off in the middle and walk away, nobody can stop you. With a girl, you've got responsibilities in doing it; with a prostitute, it doesn't matter. Is that why?

Speaker 1. No, I don't think so, not wholeheartedly, no.

\section{ExTRACT 4}

Speaker. My wife wouldn't satisfy me.

Leader. She doesn't satisfy you?

Speaker. No, she's like a lump of cold mutton. So what do you do? You go out and try to find someone else. You look for more feeling. I think that's what a lot of men do it for. Instead of that if your wife can. . ... I think the world of her, give her anything she wants. But if you're having intercourse, if you could really enjoy it, and you've got feeling there, that's all right. But she can't do nothing for you, just lies there like a lump of cold mutton. Well, you just go outside and find somebody else. You still come home. ... . I know it's the wrong thing, I know it is, all the way, but still. . . .

Leader. You would like her to show some pleasure, too. Speaker. Yes, definitely.

\section{Extract 5}

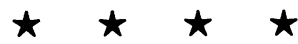

Leader. Do you think it an advantage not having to bother about cajoling a woman into agreeing? With a pick-up you really come to a bargain-I mean she's expecting it. Do you say that makes it much easier than having to bother about getting confidence?

Speaker 1. Yes, I would, definitely.

Leader. You do.'t want to be bothered with that?

Speaker 2. Yes, I think that's true. Of course, I don't think it is as good. With a prostitute, it cannot be as good because she is at it every day, so therefore it cannot be so good, and I appreciate that, but it is far easier.

Leader. Would the rest of you like to take up that theme, because it does seem that he said something very provoking in many ways.

Speaker 1 . Well, I think that is the general male attitude-that a chap has no respect for a girl that he has easy intercourse with.

Speaker 3. Convenience is the word I think of.

Speaker 1. Then again it seems a pity if you are courting a girl for some time-you are not married-and she finally relents and you have intercourse. Well if you immediately lose respect for her afterwards, in that case, I feel sorry for the girl, I think the man is to blame.

Leader. So you really distinguish two kinds of women?

Speaker 1. Not necessarily, no. I wouldn't call a girl who would have intercourse necessarily a prostitute.

\section{EXTRACT 6}

Leader. Is it your opinion that prostitutes are different from women in general? Do you distinguish between two kinds of women?

All. Yes, definitely.
Leader. Well, let's have a chat about that because that seems to have aroused your interest.

Speaker 1. Well, you look at two women, say, walking along the street, and I bet you could pick out the prostitute from the respectable woman.

Leader. In what way?

Speaker 1. There's just something about her. In nine cases out of ten a prostitute never carries a handbag-you seldom see them carrying a handbag-they're always smoking their heads off-well, I don't know, it's something-you instinctively say "that's one". You get a married woman, or a decent woman, she walks along faster, she doesn't slouch along-put it that way-she just goes along sort of normally. You just seem to pick them out easier.

Leader. Yes, from the point of view of identifying them. That may, of course, have been the kind of personality they've produced for their trade, may it not? Every trade has its personality.

Speaker 2. The personality is entirely different between a prostitute and a normal woman. From what I gatherand quite frankly I have not had much to do with them, or anything to do with prostitutes-but from what I've seen and been told, their outlook on life is entirely different from a normal woman. They're hard and bitter, and all their interest is in money. Their personal outlook on life is, to repeat, hard and callous. Whereas a normal woman, all she is interested in, if she marries her husband, is the general welfare of the family and the happiness of most people around the family.

\section{Extract 7}

Leader. Now, how is it that you've not seen any posters? Of 200 men that we enquired about before, every one of them had seen a poster in a public lavatory. Hadn't you seen them?

Speaker 1. I had just seen the normal ones which say that venereal diseases are dangerous and treatment should be obtained at once, but that was all. I mean, nothing which really impressed itself on my mind, even though in my profession it is my job really to take notice of posters.

Leader. In your work, you mean?

Speaker 1. Yes.

Leader. What about you?

Speaker 2. Oh yes, I had seen the posters. I remember you had a very large publicity campaign in the newspapers at one time, didn't you? I remember that. And I'd heard broadcasts. I'd also seen the films which you've spoken of. And, of course, I've discussed it quite freely with other men, in the office; as I say, thinking of it as something which happens to other people.

Leader. What about you-haven't you ever discussed it with other men?

Speaker 1. Well, not really. Only in the sort of thing you get at school-perhaps a dirty joke, and that's that. It was not until I discovered that I had it, and I went to the doctor who told me to go to the special treatment centre. And then I was so shocked by what he ... well, he hadn't actually told me . . . he said what it might bethat I just did not know what to do and what sort of treatment I should get. I was really disturbed by what I thought the treatment was, what I had heard the treatment was. I went and saw two friends of mine who are 
nurses, and asked them what was the treatment for it. As it happened, one of them had actually worked in a special treatment centre, and she told me exactly. . . .

Leader. What was your principal source of alarm? Was it that you had the disease that you felt, shall we say, was disgusting? Or was it that you were fearful of the kind of treatment what would be offered? Which was it?

Speaker 1. Well, both things actually. I felt "dirty" that I'd got it, and I'm an absolute coward as regards physical pain. I just can't stand it-it's as much as I can do to have a hypodermic injected into me. I just didn't know what was going to happen. I'd heard so many tales that at the time I thought were true and that I now know to be ridiculous and not what actually happens.

Leader. What sort of things?

Speaker 1. Well, needles that open like umbrellas, and I think another was red hot needles and things like that, and various other tales-it just unnerved me completely. If I hadn't spoken to my two friends I doubt whether I would have gone to a treatment centre until much later.

Leader. Well now, can I ask you this? When you had intercourse with the person from whom you were infected, did you have any idea in your mind that you might possibly contract an illness from her?

Speaker 1 . Not really, it wasn't in my thought at the time. I suppose that one does know, one does think that you can get it from anyone, almost, that you do have intercourse with. It's in the back of your mind, I suppose but it's never sort of in your thoughts at the time.

Leader. No, I see. How old are you?

Speaker 1. I'm nineteen.

Leader. And how old are you? What's your comment on his story?

Speaker 2. I'm thirty-two. I find it extremely odd. My own experience was very different. I knew all about (it) in the Army, I'd seen the films, I'd absolutely no fear of treatment, and I knew all about the miracle of penicillin. I was just extremely annoyed. I knew that I should have to stop drinking and stop having sexual intercourse-and that sums it up, I would say.

Leader. So for you it was purely a nuisance value. And you had confidence in the treatment.

Speaker 2. Yes, nuisance value. And I had absolute confidence.

Leader. You had no feeling of remorse or regret at all about the actual fact of contracting venereal disease?

Speaker 2. Yes, it would be true to say I did have some feeling of remorse, rather like a criminal-the remorse of having been caught, rather than of having committed a crime.

Leader. Now in your case did you have any feeling of guilt or remorse-I mean at the actual behaviour that you had advanced upon-or was it the fear of what might happen to you?

Speaker 1. Well, I did not feel ashamed of what I had done or sorry that I had done it. It was just the thought that I had got something which to me was extremely unusual-it was a thing that someone else might get, but it could never happen to me-that type of thing-and that was all, really, that I did feel. You see I had not discussed it with friends, mainly because, well, it's a bit infra dig.- -it's not the sort of thing to talk about. I have not got a great number of friends, and those that I do have don't talk about things like that at all.

\section{Commentary}

One of the objectives of this study was to discover clues for a more effective educational approach. Richman (1954) described the task of attempting to change behaviour problems surrounding the function of procreation as a "staggering assignment requiring something much more dynamic than information". The views of Wittkower referred to above confirm this and that author went further in claiming that it was inaccurate to regard promiscuity as a sexual problem because this meant that prophylaxis would be aimed at the wrong target. There is no magic formula, according to Wittkower, but education should include child guidance, sex education, and mental hygiene, and in all education relating to venereal disease, more attention should be paid to neurotic motivations.

In this problem we are concerned with the transient affectionless episodes to which the term promiscuity can justly be applied. Extra-marital intercourse as such is not concerned, so that from the point of view of long-term prevention of venereal disease, efforts to promote healthy emotional development in the child are likely to be beneficial. Equipped with emotional maturity that can fuse affection and the sexual act in the right proportions, the young adult should not feel the urge for the transient relationship.

For immediate practical purposes the question we must ask is whether any of the men who took part in our discussions could have been helped to a more effective handling of their personal problems which would have avoided their running the risk of infection.

On studying the discussion it is impossible to escape the impression that all the men were attempting to rationalize their motives and had an ambivalent attitude to sexual conduct and prostitution. Their belief that there was a biological sex urge-not proved by Wittkower-was useful to them in this process of rationalization. Whether or not it is justified to disillusion them and so to remove one of their emotional props is a matter for psychiatric opinion. On the other hand, if this belief was hindering the achievement of insight into their motivations, then there would be a case for explaining the true facts as we understand them at present.

The enthusiasm with which the men took part in the discussion, particularly in view of the fact that they were sacrificing leisure in order to do so, suggests that the technique has a special value in this problem. There is also need of a new kind of film which aims at interpreting the psychodynamic concepts which are recognized to be concerned in 
promiscuity. It is not suggested that leaflets and posters giving information on venereal disease should be abandoned, although they may be effective only in that they persuade those who have run the risk of infection to attend for treatment. However, these methods need complementing with those which aim more directly at stimulating insight into motivation and therefore will prevent promiscuous behaviour. One thing which is clear is that fear of venereal disease is not a preventive factor.

\section{Summary}

Health education activities in the field of venereal diseases have been preoccupied with warning the public of the risk of contracting these diseases and directing them to centres where they may obtain treatment. This is not truly preventive in action as it disregards the importance of motivation and of the emotional attitudes which lie behind sexual promiscuity. This psychological aspect of the problem needs special study as venereal diseases can be regarded as its by-product. Certainly any new health education approach must take these factors into account.

This problem has interested certain psychiatrists, in particular Wittkower, who carried out studies of personality in relation to sexual promiscuity in 1945 and 1949. It was decided to carry out similar studies with the use of group discussion techniques with small groups of men who had attended Special Treatment Centres. Patients attended anonymously and on a voluntary basis and agreed that the discussions should be recorded.

There were three objectives-to promote free discussion on personal attitudes to VD and to sexual promiscuity; to identify personality traits which might be operative; and to obtain ideas for a more effective educational approach as distinct from propaganda.

As a result of the studies done so far it does appear that specific attitudes to prostitution exist and that there is a tendency to look upon prostitutes as distinct from other women-that is, a dual standard of conduct is displayed. It also appears that there is a belief that sexual intercourse is necessary for health.
This work is frankly experimental and this is a preliminary communication, the main interest of which is the techniques adopted for initiating and conducting group discussion.

\section{REFERENCES}

British Federation against the Venereal Diseases (1958). Med. Offi., 99, 163.

Richman, T. L. (1954). J. soc. Hyg., 40, 253.

Watts, G. O., and Wilson, R. A. (1945). Canad. med. Ass. J., 53, 119 Wittkower, E. D. (1949), In "Modern Practice in Psychological Medicine, 1949", ed. J. R. Rees, p. 103. Butterworth. London. and Cowan, J. (1944). Psychosom. Med., 6, 287

\section{Discussion en groupe avec des malades vénériens mâles}

\section{Résumé}

L'éducation médicale du public sur les maladies vénériennes consiste à avertir de leur danger et à indiquer les centres de traitement. Ces mesures de prophylaxie sociale ne sont pas complètes, car elles ne tiennent pas compte de l'importance de la motivation et des attitudes émotionnelles sur lesquelles se base la promiscuité sexuelle. Cet aspect psychologique demande des recherches spéciales, puisque les maladies vénériennes pourraient être considérées comme son produit secondaire. Toute tentative nouvelle d'education médicale du public général devra prendre en considération ces facteurs.

Ce problème a intéressé certains psychiatres, en particulier Wittkower, qui étudia la personalité par rapport à la promiscuité sexuelle en 1945 et 1949 . Ici, on a décidé de procéder à des recherches similaires en usant des méthodes de discussion en groupe et en formant dans ce but de petits groupes composés de malades visitant nos Centres de Traitement Spźcial. Les participants venaient volontairement, gardaient l'anonymat et consentaient à ce qu'on enregistre les discussions.

Il y avait trois objectifs:- encourager des discussions franches sur des attitudes personnelles aux maladies vénériennes et à la promiscuité sexuelle; identifier des traits de personalité comme possibles facteurs opératifs; et se faire une idée sur une approche éducative plus efficace et distincte de la simple propagande.

A la suite des recherches effectuées jusqu'à present, on trouve qu'il existent des attitudes spécifiques à la prostitution, et qu'il y a une tendance à regarder les prostituées comme étant différentes d'autres femmes-c'est-à-dire il se révèlent deux normes de conduite. On décèle aussi une conviction que des relations sexuelles sont nécessaires à la santé.

Ce travail est franchement expérimental et cette communication n'est que préliminaire; son intérêt principal réside dans les procédés adoptés pour organiser et conduire des discussions en groupe. 